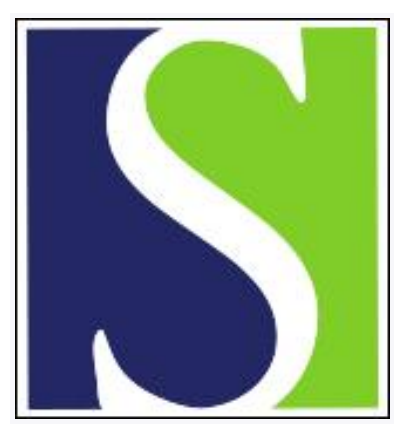

Scand J Work Environ Health 1993;19(2):96-101

https://doi.org/10.5271/sjweh.1491

Issue date: 01 Apr 1993

Mortality and cancer incidence in a cohort of rubber workers in Moscow.

by Solionova LG, Smulevich VB

Affiliation: Laboratory of Occupational Cancer, Cancer Research Center, Russian Academy of Medical Sciences, Moscow.

This article in PubMed: www.ncbi.nlm.nih.gov/pubmed/8316785

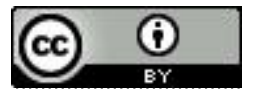




\title{
Mortality and cancer incidence in a cohort of rubber workers in Moscow
}

\author{
by Liya G Solionova, PhD, Vladimir B Smulevich, MD'
}

\begin{abstract}
SOLIONOVA LG, SMULEVICH VB. Mortality and cancer incidence in a cohort of rubber workers in Moscow. Scand J Work Environ Health 1993;19:96-101. This study evaluated the mortality and cancer incidence of 1178 men and 2492 women who had worked at least 10 years in a large rubber manufacturing facility up to the cohort assembly period between 1 January 1979 and 31 December 1983. The follow-up period was from 1 January 1979 to 31 December 1988. For all causes of death no increase in risk was observed. The male workers had a nonsignificantly increased standardized mortality ratio (SMR) for all cancers [SMR 116,95\% confidence interval (95\% CI) 90-151] and a significantly increased SMR for injuries (SMR 174, 95\% CI 111-257). For the men the all-cancer standardized incidence ratio (SIR) was 146 (95\% CI 119-172), and the SIR for brain cancer was significantly greater than 100 (SIR 500, 95\% CI 233-767). Among the female workers only a significant excess risk for laryngeal tumors (SIR 1430, 95\% CI 172-5160) was found. Because of the limited amount of data and the many subgroups formed, the occupational genesis of the cancer excess should not be overinterpreted. In addition, there was a possibility of confounding from smoking and other nonoccupational factors.
\end{abstract}

Key terms: cohort study, epidemiology, occupational cancer, rubber chemicals.

Workers in the rubber industry are exposed to carcinogenic substances (1). In Russia, cancer mortality has been determined for workers in two tire-manufacturing plants. Significantly increased risks for cancer of the lung, stomach, and total digestive tract were revealed for the men and women employed in both plants (2).

In the present paper our objective was to assess the mortality and cancer incidence of workers in still another rubber plant in relation to the work processes and exposures.

\section{Subjects and methods}

The worksite under study was a Moscow plant producing rubber footwear and other rubber goods. This plant has been operating for over 100 years.

The cohort consisted of 3670 workers ( 1178 men and 2492 women), employed for 10 or more years up to the cohort assembly period between 1 January 1979 and 31 December 1983. Of this number 2090 were still employed, 968 had retired, 121 had died, and 443 had left the plant for various reasons as of 31 December 1983. The follow-up period was from 1 January 1979 to 31 December 1988.

Laboratory of Occupational Cancer, Cancer Research Center of the Russian Academy of Medical Sciences, Moscow, Russia.

Reprint requests to: Dr LG Solionova, Cancer Research Center, Laboratory of Occupational Cancer, Kashirskoye shosse 24, Moscow 115478, Russia.
Sources of data for the follow-up were the central address bureaus of Moscow and other cities, central and local registry offices, the files and records of out-patient cancer clinics and hospitals, and pathology departments of hospitals. Initially, the address and vital status of each member of the cohort were obtained from the central address bureaus, and the cohort was stratified with special reference to district of residence.

Subsequently, the decedents' cause of death was determined via the registry offices of regions in which they had died. For all of the subjects who had cancer mentioned on their death certificate, an attempt was made to verify the diagnosis. If a person died in a hospital, the hospital was contacted and further details were sought from the medical history and the autopsy protocol. All of the living and deceased members of the cohort (including those who died of causes other than cancer) were followed through registration in local cancer departments of out-patient clinics according to their place of residence. If a cancer case was identified through such a department, the patient's medical record was reviewed to verify the diagnosis.

In Moscow all cases of cancer of the oral cavity, pharynx, and urinary organs are sent to special centers in the central out-patient cancer clinic of Moscow. The entire cohort was followed via the records of these centers.

During the follow-up period, a total of 327 deaths ( 195 men and 132 women) were recorded in the cohort, 107 of which were due to cancer (66 men and 41 women). The number of cancer cases, including living patients, was 155 ( 84 men and 71 women). In 
all, 3327 persons were alive, and for $18(0.5 \%)$ the vital status was unknown. Those with unknown vital status were either persons under 40 years of age who had left Moscow without having left their new address or women under 40 years of age who could have changed their name due to marriage. Both categories were included in the cohort as living on 31 December 1988. A death certificate could not be located for one $(0.3 \%)$ of the deceased employees. The causes of death and the sites of cancer were coded according to the International Classification of Diseases, ninth revision.

The plant has retained complete personnel records pertaining to department and job. These data provided the basis for the subsequent subdivision of the cohort into occupational groups (ie, production and nonproduction workers). The department or shop data were supplemented by environmental measurements. Using the latter, we grouped the exposed workers as follows: (i) workers in the preparatory shop, where the most unfavorable work conditions were revealed (this shop is situated in a separate building); (ii) curing or vulcanizing workers exposed to rubber fumes and vulcanizing gases; (iii) other occupations (building, preparation, assembly, transport, inspection, finishing, maintenance, etc).

The computation of the expected values was based on statistics of mortality and cancer incidence for the Moscow population in 1979-1988. The computations were performed according to the person-years method, specified in terms of gender, calendar years, and 10-year age groups (table 1). The summary risk measure obtained was the standardized incidence or mortality ratio (SIR or SMR, respectively) computed as (observed/expected) $\times 100$, with the respective $95 \%$ confidence interval $(95 \% \mathrm{CI})$. The SIR values were examined by age at first employment in the rubber industry, years since first exposure in the rubber industry, duration of exposure in the rubber industry, cause of death, and specific cancer sites. To test for trend in the SIR values, the chi-square statistic was used (3).

Reproductive factors are potential confounders in studies of the association between occupational factors and cancer among women. To estimate their influence, we interviewed 1388 female workers older than 18 years to obtain their reproductive history. The questionnaire also included questions on smoking and drinking habits. The results were compared with the data from the female population of Moscow (4).

\section{Results}

Men

Table 2 describes the mortality patterns for the men in the cohort. There were nonsignificantly increased SMR values for all cancers and cancers of the oral cavity and pharynx, stomach, lung, bladder and kidney, and other sites and lymphoma and leukemia.
There were two significant findings, namely, an increased mortality from accidents and a decreased mortality from circulatory diseases. Other categories, including total mortality, appeared to have substantial deficits in the observed number of deaths in comparison with the expected number of deaths.

The all-cancer SIR for the men was $146(95 \% \mathrm{CI}$ 119-172), and the number of cases of brain cancer was higher than expected ( 3 versus 0.6 , SIR 500, 95\% CI 103-1460). Nonsignificant excesses of risk were found for cancer of the oral cavity and pharynx, stomach, colon, pancreas, lung, connective tissue, and prostate. Sixty-one of the 84 workers who developed cancer were occupied in production and had been exposed to occupational hazards, including all of the persons with oral cavity, colon, rectum, and gallbladder cancer. Significantly higher risks for all cancers and oral cavity cancer were found for the production workers. Two connective tissue sarcomas occurred in workers in nonproduction activities. The

Table 1. Distribution of person-years of the men and women in the cohort by age at first employment in the rubber indus. try, time since first exposure in the rubber industry, and duration of employment in the rubber industry.

\begin{tabular}{lrrrrr}
\hline & \multicolumn{2}{c}{ Men } & & \multicolumn{2}{c}{ Women } \\
\cline { 2 - 3 } \cline { 5 - 6 } Characteristic & Number & $\begin{array}{c}\text { Person- } \\
\text { years }\end{array}$ & & Number & $\begin{array}{c}\text { Person- } \\
\text { years }\end{array}$ \\
\hline Age at first employment & & & & & \\
$\quad<40$ years & 1015 & 9044 & & 2354 & 22170 \\
$\quad \geq 40$ years & 163 & 1258 & & 138 & 1184 \\
Time from first exposure & & & & & \\
$10-19$ years & 235 & 3612 & & 474 & 6694 \\
$20-29$ years & 475 & 4275 & & 653 & 7642 \\
$\geq 30$ years & 468 & 2415 & & 1365 & 9018 \\
Duration of employment & & & & & \\
10-19 years & 382 & 4456 & & 682 & 7945 \\
$20-29$ years & 457 & 4051 & & 755 & 7865 \\
$\geq 30$ years & 339 & 1795 & & 1055 & 7544 \\
\hline Total & 1178 & 10302 & & 2492 & 23354 \\
\hline
\end{tabular}

Table 2. Observed and expected numbers of deaths and the standardized mortality ratio (SMR) for selected causes of death among the male workers in the cohort. $\mathrm{O}=$ observed number of deaths, $\mathrm{E}=$ expected number of deaths, $95 \% \mathrm{Cl}=95 \% \mathrm{con}$ fidence interval)

\begin{tabular}{lrrrr}
\hline Cause of death $^{\mathrm{a}}$ & $\mathrm{O}$ & $\mathrm{E}$ & SMR & $95 \% \mathrm{CI}$ \\
\hline All causes (000-999) & 195 & 214.4 & 90 & $78-103$ \\
All cancers (140-208) & 66 & 56.6 & 116 & $90-151$ \\
$\quad$ Oral cavity, pharynx (140-149) & 4 & 2.0 & 198 & $54-507$ \\
Esophagus (150) & 1 & 2.2 & 45 & $1-250$ \\
Stomach (151) & 16 & 12.7 & 126 & $72-204$ \\
Colon (153) & 2 & 3.3 & 60 & $7-216$ \\
Rectum (154) & 2 & 2.5 & 81 & $10-292$ \\
Other digestive organs (155-159) & 4 & 4.5 & 88 & $24-225$ \\
Lung (162) & 21 & 16.7 & 125 & $77-191$ \\
Prostate (185) & 1 & 1.7 & 58 & $1-323$ \\
Bladder, kidney (188-189) & 3 & 3.2 & 93 & $19-271$ \\
Other sites (190-199) & 4 & 1.8 & 222 & $60-568$ \\
Lymphoma and leukemia (200-208) & 5 & 2.8 & 178 & $57-414$ \\
Circulatory diseases (390-459) & 81 & 109.8 & 73 & $58-91$ \\
Injuries (800-999) & 24 & 13.8 & 174 & $111-257$ \\
\hline
\end{tabular}

a Code of the International Classification of Diseases, ninth revision, in parentheses. 
Table 3. Cancer incidence by site among the male workers in the cohort. $(\mathrm{O}=$ observed number of cancer cases, $\mathrm{E}=\mathrm{expected}$ number of cancer cases, SIR = standardized incidence ratio)

\begin{tabular}{|c|c|c|c|c|c|c|c|c|c|}
\hline \multirow{2}{*}{ Site of tumora } & \multicolumn{3}{|c|}{ Production } & \multicolumn{3}{|c|}{ Nonproduction } & \multicolumn{3}{|c|}{ Total } \\
\hline & 0 & $E$ & SIR & 0 & $E$ & SIR & 0 & $E$ & SIR \\
\hline $\begin{array}{l}\text { Oral cavity, pharynx }(141-149) \\
\text { Esophagus (150) } \\
\text { Stomach }(151) \\
\text { Colon (153) } \\
\text { Rectum (154) } \\
\text { Gallbladder (156) } \\
\text { Pancreas (157) } \\
\text { Larynx (161) } \\
\text { Lung (162) } \\
\text { Bone, connective tissue (170-171) } \\
\text { Skin (172-173) } \\
\text { Prostate (185) } \\
\text { Bladder (188) } \\
\text { Kidney (189) } \\
\text { Brain (191) } \\
\text { Other sites (194-199) } \\
\text { Lymphoma and leukemia (200-208) }\end{array}$ & $\begin{array}{r}6 \\
1 \\
11 \\
3 \\
3 \\
1 \\
2 \\
2 \\
17 \\
- \\
3 \\
3 \\
1 \\
2 \\
1 \\
4\end{array}$ & $\begin{array}{l}1.9 \\
1.4 \\
8.1 \\
2.3 \\
1.9 \\
0.26 \\
1.3 \\
1.6 \\
10.6 \\
0.0 \\
0.0 \\
1.2 \\
1.4 \\
1.0 \\
0.4 \\
1.3 \\
1.35\end{array}$ & $\begin{array}{r}303^{\star} \\
69 \\
135 \\
131 \\
155 \\
384 \\
153 \\
121 \\
160 \\
0 \\
0 \\
247 \\
211 \\
93 \\
454 \\
78 \\
296\end{array}$ & $\begin{array}{l}- \\
-7 \\
- \\
- \\
1 \\
- \\
6 \\
2 \\
2 \\
1 \\
1 \\
-1 \\
-1\end{array}$ & $\begin{array}{l}0.0 \\
0.0 \\
3.6 \\
0.0 \\
0.0 \\
0.0 \\
0.6 \\
0.0 \\
4.5 \\
0.1 \\
1.1 \\
0.7 \\
0.7 \\
0.0 \\
0.16 \\
0.0 \\
0.6\end{array}$ & $\begin{array}{r}0 \\
0 \\
190 \\
0 \\
0 \\
0 \\
163 \\
0 \\
131 \\
1820^{*} \\
181 \\
129 \\
138 \\
0 \\
625 \\
0 \\
169\end{array}$ & $\begin{array}{r}6 \\
1 \\
18 \\
3 \\
3 \\
1 \\
3 \\
2 \\
23 \\
2 \\
2 \\
4 \\
4 \\
1 \\
3 \\
1 \\
5\end{array}$ & $\begin{array}{r}2.6 \\
2.0 \\
11.7 \\
3.4 \\
2.8 \\
0.4 \\
1.9 \\
2.2 \\
15.1 \\
0.4 \\
3.5 \\
1.9 \\
2.1 \\
1.5 \\
0.6 \\
1.8 \\
1.9\end{array}$ & $\begin{array}{r}225 \\
48 \\
153 \\
87 \\
106 \\
250 \\
157 \\
88 \\
152 \\
512 \\
56 \\
202 \\
186 \\
65 \\
500^{\star} \\
56 \\
257\end{array}$ \\
\hline All sites $(140-208)^{b}$ & 61 & 39.7 & $153^{*}$ & 23 & 17.7 & 129 & 84 & 57.3 & $146^{\star}$ \\
\hline
\end{tabular}

a Code of the International Classification of Diseases, ninth revision, in parentheses.

b The category "all sites" includes two tumors that are not distinguished in the general statistics. They are tumors of the retroperitoneal space (158) and testis cancer (186).

* $P<0.05$.

Table 4. Observed and expected numbers of deaths and the standardized mortality ratio (SIR) for selected causes of death among the female workers in the cohort. $(\mathrm{O}=$ observed number of deaths, $\mathrm{E}=$ expected number of deaths, $95 \% \mathrm{Cl}=95 \%$ confidence interval)

\begin{tabular}{lrrrc}
\hline Cause of deatha & O & E & SMR & $95 \% \mathrm{Cl}$ \\
\hline All causes (000-999) & 132 & 193 & 68 & $57-80$ \\
All cancers (140-208) & 41 & 56.7 & 72 & $51-98$ \\
Stomach (151) & 7 & 10.2 & 68 & $27-140$ \\
Colon (153) & 2 & 4.7 & 42 & $5-151$ \\
Rectum (154) & 4 & 3.3 & 121 & $32-309$ \\
Other digestive organs (155-159) & 6 & 4.6 & 128 & $47-279$ \\
Larynx (161) & 2 & 0.11 & 1820 & $220-6560$ \\
Lung (162) & 2 & 3.7 & 54 & $6-194$ \\
Skin (172-173) & 1 & 0.75 & 133 & $3-740$ \\
Breast (174) & 6 & 10.4 & 57 & $21-124$ \\
Uterus (181-182) & 1 & 2.3 & 43 & $1-239$ \\
Ovary (183) & 5 & 5.1 & 97 & $31-226$ \\
Other sites (190-199) & 2 & 2.5 & 79 & $9-285$ \\
Lymphoma and leukemia (200-208) & 3 & 3.2 & 94 & $19-274$ \\
Circulatory diseases (390-459) & 61 & 100.8 & 60 & $46-78$ \\
Injuries (800-999) & 11 & 7.3 & 149 & $74-267$ \\
\hline
\end{tabular}

a Code of the International Classification of Diseases, ninth revision, in parentheses.

difference in the incidence patterns of the production and nonproduction workers was not significant (table 3).

A significantly increased risk was found for the men in some occupational groups. Thus the incidence of brain cancer was significantly higher than expected among the workers exposed to hazards in the preparatory shop, where compounding, weighing, and mixing took place ( 2 observed, 0.12 expected, SIR $1670,95 \%$ CI 189-5640). Among those who had worked in this shop for 10-19 years, a significant excess of colon cancer was found ( 2 observed, 0.21 expected, SIR $952,95 \%$ CI $115-3440$ ). Those employed in this shop for $\geq 30$ years had a higher number of cases of lung cancer than expected ( 3 ver- sus 0.42 , SIR 714, 95\% CI 147-2090). In 1949 open machines for mixing raw rubber materials were substituted in the preparatory shop by closed models. In 1960 granulated soot replaced the powdery compound used earlier. All of the workers with lung cancer had been employed before 1960 ( 7 observed, 1.99 expected, SIR $351,95 \%$ CI $141-723$ ).

Five of the six men with oral cavity cancer and 16 of the 23 with lung cancer were in the group exposed to hot rubber fumes or vulcanizing gases. The increased risk of these tumors was significant for this group (5 observed, 1.59 expected, SIR 200, 95\% CI 114-334).

An excess in stomach cancer risk was found for the men in the large group of workers associated with building, assembly, transport, inspection, finishing, and the like (12 observed, 5.8 expected, SIR 209, 95\% CI 107-366). An increased number of lymphomas and leukemias was also revealed for these men (4 observed, 0.95 expected, SIR $420,95 \%$ CI $114-$ 1080). Pancreas cancer risk was significantly higher among the workers employed for $\geq 30$ years in this group ( 2 observed, 0.18 expected, SIR $1110,95 \% \mathrm{CI}$ 134-3240).

The analysis of cancer incidence according to time characteristics revealed a significant positive trend for the SIR values of oral cavity cancer and the category lymphoma and leukemia with respect to time since first exposure. The incidences were significantly increased for the workers with $\geq 30$ years since first exposure $(\mathrm{P}<0.05)$. The employees who entered the plant at the age of $<40$ years had a significantly higher all-cancer risk and risk of oral cavity cancer. No other time-trend relations were found because of the small numbers of observed cases. 
Table 5. Cancer incidence by site among the female workers in the cohort. $(O=$ observed number of cancer cases, $E=$ expected number of cancer cases, SIR = standardized incidence ratio)

\begin{tabular}{|c|c|c|c|c|c|c|c|c|c|}
\hline \multirow{2}{*}{ Site of tumora } & \multicolumn{3}{|c|}{ Production } & \multicolumn{3}{|c|}{ Nonproduction } & \multicolumn{3}{|c|}{ Total } \\
\hline & 0 & $\mathbf{E}$ & SIR & 0 & $\mathbf{E}$ & SIR & 0 & $\mathbf{E}$ & SIR \\
\hline Stomach (151) & 8 & 8.4 & 94 & - & 0.0 & 0 & 8 & 9.9 & 80 \\
\hline Colon (153) & 2 & 4.9 & 40 & 1 & 0.8 & 116 & 3 & 5.7 & 52 \\
\hline Rectum (154) & 4 & 3.5 & 113 & 1 & 0.6 & 169 & 5 & 4.0 & 122 \\
\hline Gallbladder (156) & 3 & 0.9 & 333 & - & 0.0 & 0 & 3 & 1.0 & 283 \\
\hline Pancreas (157) & 3 & 1.5 & 200 & - & 0.0 & 0 & 3 & 1.7 & 168 \\
\hline Larynx (161) & 2 & 0.13 & $1540^{*}$ & - & 0.0 & 0 & 2 & 0.14 & $1430^{*}$ \\
\hline Lung (162) & 2 & 2.8 & 69 & - & 0.0 & 0 & 2 & 3.3 & 59 \\
\hline Skin (172-173) & 5 & 5.2 & 95 & - & 0.0 & 0 & 5 & 6.0 & 83 \\
\hline Breast (174) & 8 & 16.9 & $47^{\star}$ & 3 & 2.3 & 127 & 11 & 19.3 & 57 \\
\hline Cervix (180) & 2 & 4.8 & 41 & - & 0.0 & 0 & 2 & 5.4 & 36 \\
\hline Uterus (182) & 4 & 5.6 & 70 & - & 0.0 & 0 & 4 & 6.4 & 62 \\
\hline Ovary (183) & 8 & 4.8 & 166 & 1 & 0.6 & 149 & 9 & 5.4 & 164 \\
\hline Vulva (184) & - & 0.0 & 0 & 2 & 0.06 & $3330^{*}$ & 2 & 0.3 & 571 \\
\hline Bladder (188) & 1 & 0.5 & 192 & - & 0.0 & 0 & 1 & 0.6 & 163 \\
\hline Kidney (189) & 2 & 1.1 & 172 & - & 0.0 & 0 & 2 & 1.3 & 149 \\
\hline Thyroid gland (193) & 1 & 1.4 & 68 & - & 0.0 & 0 & 1 & 1.6 & 60 \\
\hline Other sites $(194-199)$ & 2 & 1.7 & 115 & - & 0.0 & 0 & 2 & 2.0 & 99 \\
\hline Lymphoma and leukemia $(200-208)$ & 4 & 2.2 & 179 & - & 0.0 & 0 & 4 & 2.6 & 153 \\
\hline All sites $(140-208)^{b}$ & 63 & 69.5 & 91 & 8 & 11.0 & 73 & 71 & 80.5 & 88 \\
\hline
\end{tabular}

a Code of the International Classification of Diseases, ninth revision, in parentheses.

b The category "all sites" includes two tumors that are not distinguished in the general statistics. They are peritoneal mesothelioma (158) and melanoma of the eye (190).

$* \mathrm{P}<0.05$.

\section{Women}

The observed number of deaths from all causes, cancer, and circulatory diseases was significantly lower among the women than expected, while the mortality from injuries was nonsignificantly greater than expected. No excess risk was found for death from cancer of the stomach, colon, lung, breast, cervix, uterus, and other sites or leukemia and lymphoma (table 4).

The all-cancer SIR and the SIR values for several cancer sites (stomach, colon, lung, skin, breast, cervix, uterus) were lower than expected among the women. A significant excess risk was only found for tumors of the larynx. The analysis of cancer incidence in accordance with the women's occupations showed that 63 of the 71 women who had cancer worked in production. As seen in table 5, among the women in production, a nonsignificant excess was found for cancer of the gallbladder, pancreas, ovary, kidney, bladder, and lymphatic and hematopoietic systems. However, the difference between the women in production and nonproduction was not significant.

Two larynx cancers occurred in women working in the preparatory shop ( 2 observed, 0.02 expected, SIR $10000,95 \%$ CI 2060-29200). One of them was a heavy smoker, but the other did not smoke. In this shop a slight excess for cancer of the rectum, gallbladder, and other sites and leukemia was also found for the women, but they were single observed cases. Both the women with cancer of the larynx were first employed before 1949. There were no cancer cases recorded for the women employed after 1960.
At the plant under study a large group of women worked at the pressing machines as pressers. An excess of gallbladder cancer was revealed for this group ( 2 observed, 0.16 expected, SIR $1270,95 \%$ CI 154 4590).

Two women in the group of other occupations had vulva cancer. One worked in the warehouse for textile materials, and the other was a cleaner who worked throughout the plant and was exposed to general plant contamination.

A histologic examination verified peritoneal mesothelioma in a 59-year-old woman employed for 34 years in production. During the first five years she had handled rubber sheets powdered by talc in the preparatory shop.

Except for larynx cancer, ovary cancer was the only form of cancer with an excess risk in the time category 20-29 years since first employment. All of the ovary cancers were revealed among the women who had $\geq 20$ years since first exposure and who had entered rubber production at an active reproductive age. No time-trend relations were found for the female rubber workers when all of the groups were combined.

\section{Discussion}

The evidence presented in this paper confirmed an increased risk of cancer in rubber production. A striking difference was noted in the expected numbers of deaths and diseases due to cancer. This finding illustrates a problem which must be considered in any epidemiologic study taking place in Moscow, where there are two separate systems used to register un- 
related mortality and cancer incidence. The first is based on death notifications forwarded by physicians to the General Statistical Office of Moscow. This office receives information on all deceased persons registered as permanent Moscow residents and also nonresidents who die and are buried in Moscow. The latter category consists of persons without permanent Moscow residence (ie, old parents having permanent registration elsewhere but living with their children in Moscow, persons of the lowest social class not having their own homes, provincial patients treated and deceased in Moscow hospitals and buried in Moscow, etc). Living persons of this category are not included as a part of the Moscow population.

In Moscow, incidence data are concentrated in the statistics department of the central out-patient cancer clinic. One can obtain primary information, including postmortem information, about all cancer cases concerning permanent Moscow residents only. As a result of the existence of different sources of data and the variations in their contents, we have presented SIR values rather than SMR values for some cancer sites, particularly for the men. The data on cancer incidence are more reliable than those on mortality under the conditions prevalent in Moscow.

The workers in the preparatory shop showed an increased risk of brain cancer. This occupational group was heavily exposed to dust containing talc, thiuram, carbon black, and other toxic and carcinogenic substances, including benzo[a]pyrene and carcinogenic N-nitrosamines. The measured airborne Ndimethylnitrosamine and $\mathrm{N}$-diethylnitrosamine concentrations ranged from $0.05 \mu \mathrm{g} \cdot \mathrm{m}^{-3}$ up to hundreds of micrograms per cubic meter (5). Exposure to Nnitrosamines has been presumably linked with the occurrence of brain tumors (6).

There was a significantly increased incidence of total cancers and tumors of the oral cavity, lung, and stomach and also lymphoma and leukemia among some of the occupational groups of male rubber workers. The influence of vulcanization gases and rubber fumes on lung cancer risk has been described by British researchers (7). As was shown by our hygienic studies, the highest concentrations of benzo[a]pyrene, sometimes exceeding the occupational exposure limit of $0.15 \mu \mathrm{g} \cdot \mathrm{m}^{-3}$, occurred around the pressing machines and vulcanizing boilers. During some rubber pressing operations, acrylonitrile (a possible human carcinogen) was present at levels equaling the occupational exposure limit $\left(0.5 \mathrm{mg} \cdot \mathrm{m}^{-3}\right)(5)$.

Smoking is the leading etiologic factor in the development of oral cavity cancer and lung cancer, the higher risks of which were found among those exposed to rubber fumes and vulcanizing gases. We have no data available on the men's smoking habits however. An interview of a small group of volunteers $(47$ men) revealed that about $80 \%$ smoked. A similar estimate was given by plant physicians. At the same time $13 \%$ of a group of female volunteers $(\mathrm{N}=173)$ smoked. This percentage is very close to the results of a questionnaire survey of 1388 female workers, according to which $14.7 \%$ smoked. Thus we think that the estimate of $80 \%$ for smoking male workers is close to the actual figure. This percentage is higher than that for the Moscow population, in which $44.2 \%$ of the men and $10 \%$ of the women smoke (8).

As reported much earlier by the British Registrar General, cancer excess was found for the buccal cavity and pharynx among skilled rubber workers in 1920-1922 and 1929-1931 (9). Later, higher mortality rates due to this cause were shown in two studies by Mancuso and his co-workers among rubber workers in Ohio, in the United States $(10,11)$. These results have not yet been confirmed. Our results are in agreement with them however. It follows therefore that the oral cavity and pharynx can be target organs for rubber industry hazards. The differences between the incidence patterns of the male and female workers were presumably due to the differences in the extent of smoking among the men and women. On the other hand, heavy smoking among male workers would be expected to promote other fatal diseases, such as cardiovascular diseases, which was actually not the case. It is noteworthy that female workers do not work in some of the heavy operations such as mixing, milling, vulcanization in large boilers, and coating shoes with varnish. These operations are considered to be the most hazardous to health.

Thus the increased risk of the tumors concerned was probably the result of a combined action of occupational and life-style factors.

According to an earlier study (12) dust should have proved to be the agent that induced an increased risk of stomach cancer among the rubber workers, but there was no excess of stomach cancer among the compounders and mixers in the cohort under study. There were more tumors of this site, as well as leukemias and lymphomas, than expected in the group including the many other production occupations. The workers in this group were exposed to general contamination that occurs along the production line.

Talc has been shown to be an agent that produces increased stomach cancer incidence among exposed persons (13). It can be contaminated by asbestos, and, if so, is considered to be carcinogenic to humans (14). The X-ray diffractometric analysis of the talc brands used for the last 20 years in the plant under study revealed no asbestos. Nevertheless, a case of peritoneal mesothelioma, even only a single case as found in this study, should not be neglected. It should be noted that pleural mesotheliomas in rubber workers were found in another recent study (15).

Another finding that deserves attention is the specificity of the pattern of reproductive cancer in relation to site, namely, a lower than expected risk of breast, uterus, and cervix cancer and an excess of ovary tumors. Also notable was the change in the ratio breast:ovary cancer [ie, $0.9(9: 11)$ versus $0.3 \mathrm{ex}-$ 
pected]. This shift was more pronounced for the female workers in main production (1.0 or $8: 8)$. The same trend has been shown by American authors (16, 17).

The questionnaire findings demonstrated that the female workers were similar to other women in the Moscow population in respect to the main reproductive risk factors. Thus the average number of children born by one woman was 1.53 versus 1.69 for the Moscow female population. Age at first childbirth did not differ significantly from the population level either (23.3 and 23.1 years, respectively). Altogether $83.7 \%$ of the female workers had induced abortions in their reproductive history. The average number was 2.78 versus 2.40 for the Moscow population $(P<0.05)$. Hence, the reproductive behavior of the female rubber workers could not be considered to be a confounding factor, nor could it be considered a "protective" factor as is first childbirth at $<20$ years of age, number of children more than three, and use of contraception to control birth rate. Thus the revealed difference in the pattern of reproductive cancers mainly depended on occupational factors.

The two vulva tumors found in the cohort are presumably not just a chance finding either. Both tumors developed on the basis of kraurosis. This site of cancer had not been found in female rubber workers before, but vulval kraurosis is one of the typical gynecologic diseases of this occupational group (18). Incidentally, two more cases of vulval kraurosis were recorded in the cohort during the follow-up period. Hence, an important area of further epidemiologic research is the cumulative effect of the factors involved in the rubber industry on the risk of female reproductive cancers.

For some causes of death, such as accidents and suicides, social factors are important. Of the 35 deaths due to these causes, 29 occurred among the production workers. Although these workers are from a lower social group, an effect of specific job hazards is also possible.

Because of the limited amount of data and the many subgroups formed, the occupational genesis of the cancer excess should not be overinterpreted. Due to the same reason we failed to find exposure-effect relations. In addition, there was the possibility of confounding from smoking and other nonoccupational factors. It would be clearly desirable to continue research on cancer in the rubber industry in Russia to estimate the specificity between local conditions and cancer risk.

\section{Acknowledgments}

The authors gratefully acknowledge the programming and technical assistance received from Dr DV Samoylov.

\section{References}

1. International Agency for Research on Cancer (IARC). Rubber Industry. Lyon: IARC, 1982. (IARC monographs on the evaluation of the carcinogenic risk of cancer to human; vol 28).

2. Kostukovskaya AV, Lebedeva NV, Slivko-Kolchik SV. Mortality among employees in tyre industry [in Russian]. Ind Hyg Occup Dis [in Russian] 1991;11:3-6.

3. Breslow NE, Day NE. Statistical methods in cancer research; vol II (The design and analysis of cohort studies). Lyon: International Agency for Research on Cancer, 1987. (IARC scientific publication; no 82.)

4. Arhangelskiy V. Reproductive behavior and valuable orientation of urban population [in Russian]. In: Medkov VM, ed. Urban and rural family [in Russian]. Moscow: Edition Misl, 1987:21-44.

5. Solionova LG, Smulevich VB, Turbin EV, Krivosheyeva LV, Plotnikov JV. Carcinogens in rubber production in the Soviet Union. Scand J Work Environ Health 1992;18:120 -3.

6. Preston-Martin S, Mack W, Henderson BE. Risk factors for gliomas and meningiomas in males in Los Angeles County. Cancer Res 1989;49:6137-43.

7. Sorahan T, Parkes HG, Veys CA, Waterhouse JAH. Cancer mortality in the British rubber industry: 19461980. Br J Ind Med 1986;43:363-73.

8. International Agency for Research on Cancer (IARC). Tobacco: a major international health hazard. Lyon: IARC, 1986. (IARC scientific publications; no 74.)

9. Case RA, Hosker ME. Tumor of the urinary bladder as an occupational diseases in rubber industry in England and Wales. Br J Prev Soc Med 1954;8:39—54.

10. Mancuso TF, Brennan MJ. Epidemiological considerations of cancer of the gallbladder, bile ducts and salivary glands in the rubber industry. J Occup Med $1970 ; 12: 333-41$.

11. Mancuso TF, Ciocco A, El-Attar AA. An epidemiological approach to the rubber industry: a study based on departmental experience. J Occup Med 1976;10: $213-32$

12. Wright WE, Bernstein L, Peters JM, Garabrandt DH, Mack TM. Adenocarcinoma of the stomach and exposure to occupational dust. Am J Epidemiol 1988; 128:64-73.

13. Katsnelson BA, Mokronosova KA. Non-fibrous mineral dust and malignant tumors: an epidemiological study of mortality. J Occup Med 1979;21:15-20.

14. International Agency for Research on Cancer (IARC). Overall evaluations of carcinogenicity: an updating of IARC monographs, volumes $1-42$. Lyon: IARC, 1987. (IARC monographs on the evaluation of carcinogenic risks to humans; suppI 7.)

15. Negri E, Piolatto G, Pira E. Cancer mortality in a northern Italian cohort of rubber workers. $\mathrm{Br} \mathrm{J}$ Ind Med 1989;46:624-27.

16. Delzell E, Monson RR. Mortality among rubber workers: V. processing workers. J Occup Med 1982;4: $539-45$.

17. Andjelkovich D, Talbee J, Blum S. Mortality of female workers in a rubber manufacturing plant. $\mathrm{J}$ Occup Med 1978;20:409-13.

18. Novikov UP, Alipov VI, Beskrovnaya NI. The ways of decreasing gynecological morbidity among female rubber workers [in Russian]. In: Kasparov AA, Volkova ZA, ed. Republic selected articles: health protection of females - industrial workers [in Russian]. Moscow: Institute of Industrial Medicine and Occupational Diseases Press, 1977:34-6.

Received for publication: 22 July 1991 